\title{
FAKTOR-FAKTOR YANG MEMPENGARUHI PENATAUSAHAAN BARANG MILIK DAERAH DI KABUPATEN YAHUKIMO
}

\author{
Riswanjaya Tandibiring ${ }^{1}$ \\ jurnalmkd@gmail.com \\ Paulus K. Allo Layuk ${ }^{2}$ \\ Pascal967@gmail.com \\ Anthonius Citra Wijaya ${ }^{3}$ \\ anthoniuscitra@gmail.com
}

\begin{abstract}
This study aims to identify determinants in managing the goods for local government in Yahukimo regency. The research question designed was what were the determinants of the goods for local government management? The aspects in this research comprised of; 1) bookkeeping, inventory and reporting which were based on registration process of the goods for local government; and 2) the recording that is based on category and codification of the goods for local government.

The management of goods for local government is mandated under the Regulation of Ministry of Home Affairs no. 17 in 2007 titled Technical Management of The Goods for Regional/Local Governments. According to this regulation, the goods for local government management is defined as assets management activities that are consist of bookkeeping, inventory and reporting for goods of local governments in Indonesia.

A qualitative research method was applied to obtain descriptive data. An in-depth interview technique was used to collect qualitative data through interviewing key informants. The key informants were selected based on their major involvement in managing goods of the local governments in 5 local agency units in Yahukimo regency. The 5 local agencies were from Forestry, Health, Agriculture, Fishery and Plantation Service, the Regional Secretariat and Financial and Assets Management Agency in Yahukimo Regency.

The results of this research revealed that the management of goods for local government in Yahukimo regency was ineffective as mandated by the Regulation of Ministry of Home Affairs no. 17 in 2007. There were some factors of which determining this ineffectiveness. The limitations of human resources in terms of the qualities as well as quantities, the constraints of budget for the goods management, and low coordination within local government agencies were some of the identified caused of the ineffectiveness. From the inventory management context, the causes of ineffectiveness were the low number of staff for inventory, the unavailability of costs for inventory and the low skillful treasurers for government goods. Meanwhile, the reasons of low goods management reporting were the absence of punishments and rewards systems, the low human resources capacities in regards with government goods treasurers, and low commitments from managers of the local government regarding trainings to empower their staff.
\end{abstract}

Key words: management of goods for local government, Yahukimo regency

\section{PENDAHULUAN}

Dengan ditetapkannya Undang-Undang Nomor 23 Tahun 2014 tentang Pemerintahan Daerah dijelaskan bahwa Pemerintah Pusat mendesentralisasikan

\footnotetext{
${ }_{1}^{1}$ Alumni Mahasiswa Magister Keuangan Daerah Universitas Cenderawasih

${ }^{2}$ Staf Dosen Jurusan Akuntansi Fakultas Ekonomi dan Bisnis Universitas Cenderawasih

${ }^{3}$ Staf Dosen Jurusan Akuntansi Fakultas Ekonomi dan Bisnis Universitas Cenderawasih
} 
sebagian urusan pemerintahan kepada Pemerintah Daerah. Salah satu dampak dari desentralisasi adalah adanya perubahan dalam pembagian alokasi keuangan antara Pemerintah Pusat dan Pemerintah Daerah. Perubahan pembagian alokasi keuangan dilaksanakan secara proporsional, demokratis, adil, dan transparan dengan memperhatikan potensi, kondisi, dan kebutuhan daerah hal ini sesuai dengan Undang-Undang Nomor 33 Tahun 2004 tentang Perimbangan Keuangan. Dampak lain dari adanya desentralisasi adalah pemerintah daerah memiliki kekuasaaan yang lebih luas dalam pengelolaan sumber-sumber pendapatan daerah.

Pergeseran pola pendekatan ini merupakan suatu simbol trust (kepercayaan) dari pemerintah pusat kepada daerah. Kepercayaan tersebut sekaligus mengandung sebuah harapan bagi daerah untuk kreatif menemukan solusi-solusi dari berbagai masalah yang dihadapi demi kemajuan daerah. Berkaitan dengan harapan tersebut, Mardiasmo (2002:6) juga berpendapat bahwa desentralisasi diharapkan mampu mendorong peningkatan partisipasi, prakarsa dan kreativitas masyarakat dalam pembangunan; pemerataan hasil-hasil pembangunan di seluruh daerah dengan memanfaatkan sumberdaya dan potensi yang tersedia di masing-masing daerah; dan memperbaiki alokasi sumberdaya produktif melalui pergeseran peran pengambilan keputusan publik ke tingkat pemerintah yang paling rendah.

Menurut Siregar (2004: 513), kemandirian daerah dapat dicapai melalui optimalisasi sumber-sumber penerimaan daerah. Sumber-sumber penerimaan daerah yaitu pendapatan asli daerah (PAD), dana perimbangan, pinjaman daerah, dan lain-lain penerimaan yang sah.

Terbentuknya Kabupaten Yahukimo sebagai sebuah daerah otonom diikuti dengan redistribusi aset dan sekaligus kewenangan untuk mengelola aset daerah. Mardiasmo (2002: 237) mengatakan bahwa salah satu konsekuensi dari otonomi daerah adalah bertambahnya kewenangan pemerintah daerah termasuk dalam pengelolaan aset pemerintah, yang semula menjadi kewenangan penuh pemerintah pusat beralih ke kewenangan pemerintah daerah.

Aset yang diperoleh Pemerintah Kabupaten Yahukimo, yaitu selain aset-aset yang diserahkan oleh pemerintah pusat dan provinsi, juga pembagian aset dari Kabupaten Jayawijaya sebagai kabupaten induk. Jumlah aset tetap yang dimiliki oleh Pemerintah Kabupaten Yahukimo sampai dengan Tanggal 31 Desember 2012 ditunjukkan pada tabel berikut. 
Tabel 1. Aset Tetap Pemerintah Kabupaten Yahukimo Tahun 2012

\begin{tabular}{|c|l|r|}
\hline No. & \multicolumn{1}{|c|}{ Uraian } & \multicolumn{1}{|c|}{ Jumlah (Rp.) } \\
\hline 1. & Tanah & $291.908 .456 .000,00$ \\
\hline 2. & Peralatan dan Mesin & $143.313 .736 .952,00$ \\
\hline 3. & Gedung dan bangunan & $547.042 .783 .608,20$ \\
\hline 4. & Jalan, irigasi dan instalasi & $494.712 .690 .999,00$ \\
\hline 5. & Aset tetap lainnya & $5.578 .528 .983,60$ \\
\hline 6. & Konstruksi dalam pengerjaan & $5.746 .961 .200,00$ \\
\hline
\end{tabular}

Sumber : Pemerintah Kabupaten Yahukimo, Laporan Keuangan, 2012

Konsep clear and free dapat didefinisikan sebagai kepemilikan suatu properti yang jelas secara hak kepemilikan, dokumen kepemilikan lengkap dan bebas dari tuntutan hukum, tidak berpenghuni dan tidak terkait perkara. Status clear and free dari aset-aset milik Pemerintah Kabupaten Yahukimo dapat tercapai bila Pemerintah Kabupaten Yahukimo secara tetap dan berkelanjutan melakukan tindakan-tindakan Penatausahaan Barang Milik Daerah (BMD), meliputi pembukuan, inventarisasi, dan pelaporan barang milik daerah yang berada di bawah penguasaan pengguna barang/kuasa pengguna barang.

Berdasarkan Laporan Hasil Pemeriksaan (LHP) Badan Pemeriksa Keuangan (BPK) RI Perwakilan Provinsi Papua atas LKPD Kabupaten Yahukimo dari tahun 2008 s.d tahun 2012 diketahui bahwa beberapa kelemahan terkait pengelolaan aset tetap Pemerintah Kabupaten Yahukimo diantaranya tidak terdapat rincian aset tetap. Dalam tahun 2012, Pemerintah Kabupaten Yahukimo telah melakukan inventarisasi dan penilaian kembali atas Aset Tetap yang diperoleh sebelum 31 Desember 2011 pada Bidang Aset DPKAD, namun pada tingkat SKPD belum dilakukan. Laporan Aset yang dibuat oleh Bidang Aset DPKAD telah dirinci dalam bentuk Kartu Inventaris Barang (KIB) namun KIB tersebut bukan KIB yang dibuat secara konsolidasi karena SKPD tidak membuat Kartu Inventaris Barang (KIB). Selain itu SKPD juga belum menyusun Laporan Barang Penggunaan Semesteran dan Tahunan (LBPS dan LBPT). Selanjutnya pengamanan hukum atas aset tetap berupa bukti kepemilikan belum memadai, terdapat aset tetap yang dikuasai oleh pihak yang tidak berhak, dan aset tetap yang sudah diserahkan ke masyarakat namun masih tercatat sebagai aset tetap.

Dari uraian di atas, terdapat beberapa kelemahan dalam penatausahaan barang milik daerah (BMD) yang dilakukan oleh Pemerintah Kabupaten Yahukimo sehingga penulis tertarik untuk meneliti apakah Pemerintah Kabupaten Yahukimo telah melakukan tindakan-tindakan Penatausahaan Barang Milik Daerah (BMD) terhadap aset-aset milik daerah sesuai dengan yang diamanatkan dalam Peraturan Menteri Dalam Negeri Nomor 17 Tahun 2007. 


\section{METODE PENELITIAN}

\section{Jenis dan Sumber Data}

a. Jenis data

Jenis data yang digunakan dalam penelitian ini yaitu data kualitatif yaitu data yang disajikan dalam bentuk kata-kata yang mengandung makna

\section{b. Sumber data}

> Data Primer, adalah secara langsung diambil dari objek / obyek penelitian oleh peneliti dengan cara wawancara langsung dengan pimpinan dan bendahara barang tiap SKPD yang dijadikan obyek penelitan.

$>$ Data Sekunder, adalah data yang didapat tidak secara langsung dari objek penelitian. Peneliti mendapatkan data yang sudah jadi seperti rekapitulasi asset/barang, kartu inventaris barang dll yang dikumpulkan dari berbagai SKPD yang diteliti

\section{Populasi dan Sampel}

Lokasi penelitian dilakukan pada Badan Pengelolaan Keuangan dan Aset Daerah (BPKAD) Kabupaten Yahukimo, Dinas Kehutanan Kabupaten Yahukimo, Bagian Umum SETDA Kabupaten Yahukimo, Dinas Kesehatan Kabupaten Yahukimo dan Dinas Pertanian Perikanan dan Perkebunan Kabupaten Yahukimo. Adapun subjek penelitian yang dijadikan informan, berkenaan proses pengelolaan barang milik daerah yang dilaksanakan oleh kelima SKPD tersebut adalah Kepala SKPD, Kepala Bidang Aset Badan Pengelolaan Keuangan dan Aset Daerah Kabupaten Yahukimo, Sekretaris SKPD dan Bendahara Barang.

\section{Pendekatan Penelitian}

Dalam penelitian ini, penulis menggunakan pendekatan deskriptif. Penelitian kualitatif ini tidak dimaksudkan untuk menguji hipotesis, namun merupakan gambaran terhadap objek yang diteliti dalam rentangan waktu sekarang atau rentangan waktu yang teringat oleh responden. Sehingga pemecahan masalah juga pada masa sekarang dan untuk objek yang diteliti, tidak dimaksudkan untuk generalisasi. Rancangan atau jenis penelitian deskriptif menggambarkan secara cermat terhadap suatu fenomena sosial dalam jangka waktu tertentu. 


\section{Metode Pengumpulan Data}

Tehnik pengumpulan data yang dilakukan yaitu teknik observasi, teknik wawancara, dan teknik dokumentasi dengan menggunakan alat berupa pedoman observasi (check list), panduan wawancara, dan catatan, fotocopy dan kamera foto dan recorder. Analisis data bersifat kualitatif dengan tahap terdiri dari pengumpulan data reduksi data, penyajian data, dan penarikan kesimpulan merupakan tahap akhir penelitian.

\section{Teknik Analisis}

Metode yang dilakukan dalam penelitian ini adalah menggunakan metode penelitian tematik yang tergolong penelitian kualitatif, yakni menganalisis faktor-faktor yang mempengaruhi Penatausahaan Barang Milik Daerah di Satuan Kerja Perangkat Daerah (SKPD) Kabupaten Yahukimo. Secara umum penelitian tematik bertujuan untuk memahami fenomena atau gejala sosial dengan lebih menitikberatkan pada gambaran yang lengkap tentang fenomena yang dikaji dari pada merincinya menjadi variable-variabel yang saling terkait dan dilaksanakan secara sistematis. Dengan kata lain penelitian tematik memiliki fungsi untuk meneliti dan menyajikan data sebagai berikut :

a. merupakan seperangkat penelitian yang sistematis.

b. memiliki metode yang efektif.

c. memiliki objek;

d. memiliki rumusan kebenaran-kebenaran umum

e. bersifat objektif;

f. dapat memberikan perkiraan atau prediksi.

\section{HASIL DAN PEMBAHASAN}

Proses penatausahaan barang milik daerah di Kabupaten Yahukimo masih mengacu pada Peraturan Pemerintah Nomor : 6 Tahun 2006 tentang Pengelolaan Barang Milik Negara/Daerah dan Peraturan Menteri Dalam Negeri Nomor 17 Tahun 2007 tentang Pedoman Teknis Pengelolaan Barang Milik Daerah dan Peraturan Daerah (Perda) Kabupaten Yahukimo Nomor 5 Tahun 2010 tentang Pengelolaan Barang Milik Daerah (BMD). Diharapkan dengan adanya aturan daerah yang mengikat pengelolaan BMD di Kabupaten Yahukimo maka pengelolaan BMD menjadi lebih baik dan akuntabel. Tahapan proses penatusahaan barang milik daerah meliputi: 1) Pembukuan, 2) Inventarisasi dan 3) Pelaporan. 


\section{Pembukuan}

\section{a. Dinas Kehutanan Kabupaten Yahukimo}

Penulis ingin menggambarkan proses pembukuan yang dilakukan oleh Dinas Kehutanan Kabupaten Yahukimo sebagaimana yang diungkapkan oleh Bapak Ir. Ismail Tokan selaku Kepala Dinas Kehutanan Kabupaten Yahukimo dan sdr. Gerson Kambuaya, S.H. selaku Kepala Sub Bagian Umum Dinas Kehutanan Kabupaten Yahukimo. Menurut PP Nomor 6 tahun 2006 dijelaskan bahwa yang dimaksud dengan pembukuan adalah proses pencatatan barang milik daerah ke dalam Daftar Barang Pengguna (DBP) dan ke dalam Kartu Inventaris Barang (KIB) serta dalam daftar barang milik daerah. Pengguna/kuasa pengguna barang wajib melakukan pendaftaran dan pencatatan barang milik daerah ke dalam Daftar Barang Pengguna (DBP)/Daftar Barang Kuasa Pengguna (DBKP).

Pencatatan dilakukan pada saat ada barang yang diperoleh dari hasil pengadaan tahun berjalan sebagai inventaris SKPD. Barang yang telah diadakan oleh pihak ketiga selanjutnya diperiksa oleh tim pemeriksa barang. Jika barang yang diadakan sudah sesuai dengan perjanjian/kontrak, kemudian diserahkan ke SKPD melalui berita acara serah terima barang yang ditandatangani oleh tim pemeriksa barang dan pihak ketiga. Selanjutnya panitia pemeriksa barang menyerahkan ke Bendahara Barang kemudian mencatat ke dalam blanko yang telah disiapkan.

Pembukuan asset dilakukan oleh bendahara barang SKPD ke dalam Kartu Inventaris Barang (KIB). Hal ini diungkapkan oleh Kepala Dinas Kehutanan Kabupaten Yahukimo sebagai berikut :

"Pembukuan barang milik daerah yang dilaksanakan oleh Dinas Kehutanan Kabupaten Yahukimo belum sesuai dengan ketentuan yang berlaku karena kegiatan pembukuan barang/aset belum secara detail dilakukan pendaftaran dan pencatatan barang milik daerah ke dalam Kartu Inventaris Barang/Aset (KIB) menurut penggolongan dan kodefikasi barang, (Ir. Ismail Tokan, Kepala Dinas Kehutanan Kabupaten Yahukimo)".

Baru sebagian kecil kodefikasi barang yan tercatat dalam KIB maupun KIR bahkan spesifikasi barang kadang tidak tercantum. Pencatatan barang dimuat dalam Kartu Inventaris Barang (KIB) sesuai format yang meliputi : 
1. Kartu Inventaris Barang (KIB) A Tanah,

2. Kartu Inventaris Barang (KIB) B Peralatan dan Mesin,

3. Kartu Inventaris Barang (KIB) C Gedung dan Bangunan,

4. Kartu Inventaris Barang (KIB) D Jalan, Irigasi, dan Jaringan,

5. Kartu Inventaris Barang (KIB) E Aset Tetap Lainnya,

6. Kartu Inventaris Barang (KIB) F Konstruksi dalam Pengerjaan,

Pembukuan/pencatatan barang berdasarkan KIB (Kartu Inventaris Barang) berfungsi untuk mempermudah dalam pelaporan aset yang berada pada setiap SKPD. Dari wawancara yang dilakukan, bendahara barang baru membuat KIB A - KIB F dan Kartu Inventaris Ruangan (KIR) sedangkan Buku Induk Inventaris belum dibuat. Dalam pelaksanaannya, Dinas Kehutanan Kabupaten Yahukimo belum sepenuhnya mengikuti aturan yang berlaku karena pembukuan aset masih dilakukan oleh 1 (satu) orang bendahara barang yang juga merangkap sebagai Bendahara Penerima Retribusi Hasil Hutan. Hal ini ditegaskan oleh pernyataan Kasubbag. Umum Dinas Kehutanan Kabupaten Yahukimo seperti di bawah ini :

“....dengan hanya memiliki 1 (satu) orang bendahara barang yang juga merangkap bendahara penerima iuran hasil hutan, dirasa sangat tidak mungkin, (Gerson Kambuaya, S.H. Kasubbag. Umum Dinas Kehutanan Kabupaten Yahukimo)"

Hal ini dikarenakan honor untuk bendahara penerima iuran hasil hutan tidak dialokasikan dalam Dokumen Pelaksanaan Anggaran (DPA) Dinas Kehutanan Kabupaten Yahukimo. Dari pernyataan di atas, sangat relevan dengan kondisi dimana tenaga yang ada tidak mampu untuk mengerjakan pekerjaan pembukuan dengan baik apalagi kualitas SDM bendahara barang yang masih rendah di bidang pengelolaan aset karena bendahara barang memiliki disiplin ilmu kehutanan bukan ekonomi atau akuntansi.

\section{b. Dinas Kesehatan Kabupaten Yahukimo}

Penulis melihat-lihat daftar aset yaitu Kartu Inventaris Barang (KIB) dan gudang penyimpanan aset. Kartu Inventaris Barang (KIB A - KIB F) telah dibuat. Ada beberapa barang inventaris dinas yang rusak seperti computer, printer, meja, kursi dan lemari yang tidak dilaporkan ke BPKAD untuk dihapus. Kartu Inventaris Ruangan (KIR) sudah dibuat namun tidak 
selalu diperbaharui. Sebagian aset Dinkes ada di gudang obat yang letaknya jauh dari kantor Dinkes. Gudang penyimpanan aset pada Dinkes belum memadai karena sempit.

Proses pembukuan barang milik daerah pada Dinas Kesehatan Kabupaten Yahukimo sebagaimana yang telah diungkapkan oleh bendahara barang sendiri. Erna Widyastitik, SKM bahwa proses pembukuan dilakukan setelah pihak pengada barang dan jasa menyerahkan barang ke panitia pemeriksa barang untuk diperiksa sesuai dengan buku kontrak. Setelah itu panitia pemeriksa barang menyerahkan barang tersebut kepada Bendahara Barang Dinas Kesehatan untuk selanjutnya dicatat atau dibukukan ke dalam Kartu Inventaris Barang (KIB) sesuai dengan jenis dan type barang. Barang yang masuk dan keluar dicatat setiap saat terutama yang barang medis. Penjelasan ini diperkuat dengan pernyataan bendahara di bawah ini :

"barang yang datang, diserahterimakan oleh pihak ketiga ke SKPD kemudian dicatat/dibukukan, (Erna Widyastitik, SKM., Bendahara barang Dinas Kesehatan Kabupaten Yahukimo)"

Tugas ini dilakukan langsung oleh bendahara barang Dinas Kesehatan Kabupaten Yahukimo karena belum ada PNS lain yang ditunjuk sebagai pembantu bendahara barang. Pelabelan/labelling barang belum semuanya dilakukan karena keterbatasan tenaga yang ada. Hal ini disampaikan oleh bendahara barang Dinas Kesehatan Kabupaten Yahukimo :

"saya baru 1 tahun menjadi bendahara barang, tapi saya berencana untuk tidak lagi sebagai bendahara barang karena tidak sanggup, (Erna Widyastitik, SKM. Bendahara barang Dinas Kesehatan Kabupaten Yahukimo)"

Sedangkan jumlah barang yang diadakan tiap tahun meningkat terutama obat-obatan dan peralatan medis. Pengadaan obat-obatan akan diserahkan ke pencatat barang di Gudang obat untuk selanjutnya disimpan dengan membuat Daftar Mutasi Barang.

Pengadaan barang pada Dinas Kesehatan Kabupaten Yahukimo berupa aset tetap dan aset lancar, namun porsi terbesar berada pada pengadaan aset lancar yang umur pemakaiannya kurang dari 1 tahun. Kodefikasi barang ada yang dicatat dan ada yang belum di dalam KIB maupun KIR sedangkan spesifikasi barang sudah dibuat/tercantum. 


\section{c. Dinas Pertanian Perikanan dan Perkebunan Kabupaten Yahukimo}

Pada saat mengunjungi Dinas Pertanian Perikanan dan Perkebunan Kabupaten Yahukimo penulis menemui beberapa meja yang disusun di lobi kantor. Meja-meja tersebut ternyata milik Badan Penyuluh Pertanian (BPP) Kabupaten Yahukimo yang diadakan oleh Dinas Pertanian Perikanan dan Perkebunan Kabupaten Yahukimo. Penulis menanyakan mengapa masih berada di kantor pertanian karena Kantor BPP masih tidak aman. Kantor BPP selama ini tidak difungsikan karena belum terbentuk organisasi BPP Yahukimmo. Selain itu penulis melihat daftar inventaris barang (KIB) milik dinas. Pembukuan sudah dilakukan dengan adanya bukti tersebut. Selain itu, penulis melhat juga beberapa aset dinas yang sudah rusak dan diletakkan di atas lemari dan sebagian di lorong (koridor) kantor. Terlihat masih disimpan untuk menjada kalau ada pemeriksaan.

Di bagian belakang kantor ada gudang tapi untuk peralatan pertanian seperti Alat Pertanian Kecil (APK), pupuk, bibit, alat pemompa air (Alkon) dan pakan ternak. Pencatatan mutasi barang tidak dicatat baik sehingga tidak bias ditahu berapa jumlah aset yang dibagi ke masyarakat dan yang masih ada di gudang.

Selanjutnya dijelaskan oleh Sekretaris Dinas Pertanian Perikanan dan Perkebunan Kabupaten Yahukimo ibu Rini Patiung, S.E. bahwa pembukuan aset dilakukan setelah Panitia barang memeriksa jumlah, spesifikasi dan jenis barang dengan mengacu pada buku kontrak. Setelah barang dinyatakan sesuai dengan kontrak, barulah Panitia Pemeriksa Barang menyerahkan barang ke bendahara barang SKPD untuk dibukukan sesuai tabel aset. Tugas ini dilakukan oleh 1 (satu) orang bendahara barang dan tidak ada pembantu bendahara barang. Berikut petikan pernyataan saat wawancara :

"spesifikasi barang yang diadakan pihak ketiga sering tidak sesuai dengan kontrak yang dibuat, sehingga data di SKPD tidak sama dengan data aset di BPKAD, (Rini Patiung, S.E. Sekretaris Dinas Pertanian Perikanan dan Perkebunan Kabupaten Yahukimo)".

Kodefikasi barang ada yang sudah dicatat dan ada yang belum di dalam KIB karena keterbatasan tenaga dan pengetahuan bendahara barang, begitu juga dengan spesifikasi barang yang belum semuanya dibuat. 
Dari informasi yang diperoleh, pengadaan terbanyak ada pada peralatan dan mesin yaitu alat-alat dan mesin pertanian. Pelabelan barang belum dilakukan karena keterbatasan tenaga yang ada. Berikut pernyataan Sekretaris Dinas Pertanian Perikanan dan Perkebunan Kabupaten Yahukimo:

“....karena banyaknya permohonan alat peralatan kecil (parang, sekop, kapak dan linggis) dari masyarakat atau kelompok tani sehingga tiap tahun ada peningkatan dana untuk hal itu, (Rini Patiung, S.E., Sekretaris Dinas Pertanian Perikanan dan Perkebunan Kab. Yahukimo)".

Bendahara barang juga telah membuat Kartu Inventaris Ruangan (KIR) namun tidak selalu diperbaharui. Alasannya adalah keterbatasan waktu dan tenaga yang dimiliki. Ini diakibatkan karena Dinas Pertanian Perikanan dan Perkebunan melaksanakan tugas 4 (empat) sektor karena ada selain itu ada lagi sektor Peternakan, sehingga tugas sebagai bendahara barang yang hanya berjumlah 1 (satu) orang dirasa tidak mampu melaksanakan pekerjaan sesuai dengan aturan yang berlaku. Berikut pernyataan Sekretaris Dinas Pertanian Perikanan dan Perkebunan Kabupaten Yahukimo :

"bendahara barang kami hanya 1 orang dengan kualitas SDM Aset yang kurang sehingga masih sangat dibutuhkan tenaga tambahan untuk mengelola barang, (Rini Patiung, S.E., Sekretaris Dinas Pertanian Perikanan dan Perkebunan Kab. Yahukimo)"

Pengadaan aset yang ada pada Dinas Pertanian Perikanan dan Perkebunan Kabupaten Yahukimo tiap tahun ada peningkatan dari jumlah dana pengadaan barang dan jasa yang bersumber dari dana DAK dan OTSUS, tantangan ini harus dijawab dengan menyiapkan jumlah dan SDM pengelola barang yang memiliki kualitas sebagai bendahara/pengurus dan penyimpan barang.

\section{d. Bagian Umum Setda Kabupaten Yahukimo}

Di Bagian Umum Setda Kabupaten Yahukimo penulis mendapati beberapa data terkait kartu inventaris barang (KIB) yang dibuat Bagian Umum. Ada beberapa kolom yang tidak terisi karena datanya tidak ada. Kebanyakan data spesifikasi barang yang tidak terisi. Beberapa barang inventaris kantor tidak dipakai karena rusak dan tidak dilaporkan ke BPKAD. 
Salah satu tahap proses penatausahaan barang milik daerah yaitu pembukuan aset. Proses pembukuan barang hampir sama dengan SKPD lain yang telah dipaparkan diatas, yaitu setelah dilakukan pemeriksaan jumlah, jenis dan spesifikasi barang oleh panitia pemeriksa barang barulah diserahkan kepada bendahara barang untuk dibukukan.

Dari hasil wawancara dengan Kepala Seksi Perlengkapan sdr. Vistita A. Rahayaan, S.IP., diketahui bahwa pembukuan barang milik daerah yang dilakukan oleh Bagian Umum Setda Kabupaten Yahukimo belum memenuhi standar aturan yang berlaku. Hal ini dikarenakan jumlah PNS yang bertugas dalam penatausahaan barang hanya 1 (satu) orang dengan tingkat SDM yang masih rendah dalam hal pengelolaan barang. Jika dibandingkan dengan volume pengadaan barang yang jumlahnya sangat besar karena ada 11 (sebelas) bagian pada Setda Kabupaten Yahukimo, jelas jumlah tenaga pengelola aset tersebut tidak sebanding dengan banyaknya pengadaan barang. Berikut petikan wawancara sebagai berikut

"kami ingin ada tambahan tenaga pengelola barang di Bagian Umum, tapi tidak didukung dengan pembiayaan honor. Pelatihan untuk bendahara barang sangat dibutuhkan, (Vistita A. Rahayaan, S.IP. Kasie Perlengkapan Bagian Umum Setda Kab. Yahukimo)"

Sering barang yang diadakan oleh pihak ketiga tidak sesuai dengan kontrak sehingga pencatatan yang ada pada Bagian Umum Setda Kabupaten Yahukimo tidak sama dengan data yang ada pada Badan Pengelolaan Keuangan dan Aset Daerah (BPKAD) Kabupaten Yahukimo.

Kodefikasi barang ada yang dicatat dan ada yang tidak dalam KIB dan KIR karena keterbatasan pengetahuan bendahara barang. Sedangkan spesifikasi barang belum semuanya dibuat.

Kartu Inventaris Ruangan (KIR) untuk beberapa Bagian sudah dibuat namun ada yang belum, KIR tidak selalu diperbaharui sehingga data yang ada tidak sama dengan data yang ada pada Bidang Aset BPKAD Kabupaten Yahukimo. Karena banyaknya barang yang akan dibukukan, sehingga pembukuan tidak berjalan dengan baik. Penulis tidak melihat daftar mutasi aset ke bagian-bagian pada setda yang seharusnya ada guna control arus barang masuk dan keluar. Banyak keluhan yang disampaikan oleh bendahara barang terkait pembukuan aset pada Bagian Umum. Sangat perlu untuk adanya penambahan pengurus barang karena 
saat ini bendahara barang yang ada sudah tidak mampu dalam mengelola penatausahaan maupun alur mutasi barang di lingkungan Setda Kabupaten Yahukimo.

\section{e. Badan Pengelolaan Keuangan dan Aset Daerah Kabupaten Yahukimo}

Dalam wawancara ini penulis menemui Kepala Seksi Inventarisasi dan Mutasi Aset Bidang Aset Badan Pengelolaan Keuangan dan Aset Daerah Kabupaten Yahukimo yaitu sdr. Robert Rantung, S.E. Terlihat banyak aset BPKAD yang diletakkan dalam ruangan Seksi Inventarisasi dan Mutasi Aset. Gudang penyimpanan sudah terlalu sempit dan biasanya barang elektonik cepat rusak karena kelembaban yang tinggi di Dekai dan juga banyaknya hama tikus. Beberapa blanko daftar aset diperlihatkan ke penulis. Begitupun laporan-laporan aset dari SKPD. Beberapa aset tidak disimpan baik, karena ruangan yang tidak memadai. Berikut penjelasan yang penulis dapat uraikan di bawah ini.

Pengelolaan barang milik daerah dalam proses penatausahaan untuk penyajian laporan telah dikuatkan dengan PERDA namun koordinasi belum maksimal dilakukan dengan pengelolaan aset yaitu Bidang Aset BPKAD Kabupaten Yahukimo, namun sistem dan prosedur dalam pelaksanaan untuk koordinasi telah dikuatkan dalam perda.

Bidang Aset sudah melakukan pembinaan terhadap para pengurus atau pengelola barang milik daerah di seluruh SKPD dalam pembuatan Buku Inventaris, Pembuatan Kartu Inventaris Ruangan (KIR) dan Kartu Inventaris Barang (KIB). Hal ini dikuatkan dengan petikan wawancara sebagai berikut :

"Blanko/model KIB dan KIR telah dibagi ke masing-masing SKPD disertai pendampingan oleh BPKAD namun baru beberapa SKPD yang mengisi dan mengirim kembali ke BPKAD, (Robert R., S.E. Kasie. Inventarisasi dan Mutasi Aset BPKAD Kab. Yahukimo)"

Kegiatan ini dimaksudkan supaya penatausahaan barang yang salah satu komponennya adalah pembukuan dapat disajikan dan memberikan informasi yang tepat dalam prosedur pengelolaan barang milik daerah. Untuk pelatihan mengenai pengelolaan aset di Kabupaten Yahukimo baru sekali dilaksanakan yaitu pada tahun 2014 seiring dengan dibentuknya Seksi Inventarisasi dan Mutasi Aset. 
"pelatihan baru sekali dilakukan pada tahun 2014 dan sampai sekarang belum ada pelatihan aset, sementara akhir tahun 2015 akan dicoba aplikasi komputerisasi pengelolaan aset sehingga pelaporan aset SKPD secara online, (Robert R., S.E. Kasie. Inventarisasi dan Mutasi Aset BPKAD Kab. Yahukimo)"

Pembukuan barang milik daerah yang dilakukan oleh Badan Pengelolaan Keuangan dan Aset Daerah Kabupaten Yahukimo berada pada Seksi Pendataan dan Klarifikasi Aset pada Bidang Aset. Ada 2 (dua) orang pencatat barang yaitu 1 orang PNS dan 1 orang tenaga honorer dan dibantu konsultan Aset yang dikontrak oleh BPKAD sehingga pembukuan yang dilakukan mulai ada peningkatan dari tahun sebelumnya.

Barang yang sudah diserahterimakan diartikan sebagai aset sedangkan barang yang belum diserahterimakan tidak tergolong aset. Hal ini diungkapan oleh Kasie. Inventarisasi dan Mutasi Aset Bidang Aset BPKAD Kab. Yahukimo :

"barang yang ada dikatakan sebagai aset jika barang pengadaan tersebut sudah diserahterimakan (Robert R., S.E. Kasie. Inventarisasi dan Mutasi Aset BPKAD Kab. Yahukimo)"

BPKAD selain menerima laporan pengadaan aset dari SKPD, sering melakukan pengecekan lapangan terkait laporan pembukuan aset dari SKPD, bertujuan agar pembukuan di BPKAD sama dengan SKPD. Selain itu BPKAD sering mengunjungi SKPD guna memberikan pembinaan dalam hal pembukuan barang milik daerah. BPKAD mengharapkan adanya koordinasi antara bendahara barang di setiap SKPD dengan Bidang Aset di BPKAD. Hal ini dikemukan oleh Kasie. Inventarisasi dan Mutasi Aset Bidang Aset BPKAD Kab. Yahukimo :

"bendahara barang SKPD kurang koordinasi dengan BPKAD

(Robert R., S.E. Kasie. Inventarisasi dan Mutasi Aset BPKAD Kab. Yahukimo)"

Namun kurang aktifnya pengurus dan penyimpan barang dalam pembukuan serta penyaluran barang terkadang membuat proses penerimaan dan penyaluran tidak terlaksana dengan baik, seharusnya setiap ada proses pengadaan terhadap barang, bendahara barang harus mencatatnya ke dalam buku inventaris, sehingga pada tahap proses penyaluran barang ke bidang-bidang data barang tersebut sudah terakomodir dengan baik. 


\section{Inventarisasi}

Maksud inventarisasi adalah untuk mengetahui jumlah dan nilai serta kondisi BMD yang sebenarnya, baik yang berada dalam penguasaan Pengguna Barang maupun yang berada dalam pengelolaan Pengelola Barang. Di samping itu, Pengelola dan Pengguna melaksanakan sensus barang milik daerah setiap 5 (lima) tahun sekali untuk menyusun Buku Inventaris dan Buku Induk Inventaris beserta rekapitulasi barang milik pemerintah daerah. Pengelola bertanggung jawab atas pelaksanaan sensus barang milik daerah tersebut. Hal ini dikuatkan dengan petikan wawancara kami bersama Kasie. Inventarisasi dan Mutasi Aset BPKAD Kabupaten Yahukimo :

"inventarisasi BMD di Kab. Yahukimo belum dilakukan karena keterbatasan dana, direncanakan tahun 2016 akan dilakukan inventarisasi dengan membuat suatu tim kerja, yang jadi masalah adalah ada beberapa aset yang dikerjakan tidak melalui SPMK (kerja mendahului) dan pemberian aset daerah kepada perseorangan dianggap sebagai hibah, (Robert R., S.E. Kasie. Inventarisasi dan Mutasi Aset BPKAD Kab. Yahukimo)"

Kegiatan inventarisasi dan identifikasi dimaksudkan untuk memperoleh informasi yang akurat, lengkap, dan mutakhir mengenai kekayaan daerah yang dimiliki atau dikuasai oleh pemerintah daerah. Untuk dapat melakukan inventarisasi dan identifikasi aset daerah secara objektif dan dapat diandalkan, pemerintah daerah perlu memanfaatkan profesi auditor atau jasa penilai yang independent.

Inventarisasi dilakukan dalam periode tertentu untuk memastikan jumlah barang yang ada sesuai dengan pembukuan. Ada barang yang dimiliki suatu SKPD terdiri dari banyak barang yang rusak, tidak digunakan dan kadaluwarsa, tentu saja akan membebani pembukuan. Seharusnya SKPD menginventarisasi dan melaporkan ke Bidang Aset BPKAD untuk dilakukan penghapusan dari buku aset. Penghapusan aset di Kabupaten Yahukimo baru sedikit dilakukan karena kurangnya pengetahuan dari bendahara barang SKPD. Pada tahun 2015 mulai dilakukan penghapusan aset berupa kendaraan dinas yang diadakan pada tahun 2008 dan tahun sebelumnya. Penjelasan diatas didukung oleh petikan wawancara penulis dengan Kasie. Inventarisasi dan Mutasi Aset BPKAD Kab. Yahukimo : 
"sering bendahara barang SKPD tidak melaporkan aset yang rusak dan tidak berfungsi seperti peralatan computer dan kendaraan dinas sehingga membebani pembukuan aset daerah, (Robert R., S.E. Kasie. Inventarisasi dan Mutasi Aset BPKAD Kab. Yahukimo)"

Sedangkan kalau kita melihat dari sisi pelaksanaan inventarisasi, akan banyak sekali tenaga, waktu dan biaya yang digunakan akan menjadi sesuatu yang sia-sia karena hal itu dilakukan untuk menghitung dan mengidentifikasi barang-barang yang ternyata rusak, tidak terpakai atau kadaluwarsa.

Dari hasil pengamatan pada 5 (lima) SKPD, semuanya telah melakukan inventarisasi barang persediaan dan konstruksi dalam pengerjaan yang telah dilakukan setiap tahun (Opname fisik). Sedangkan inventarisasi aset (Sensus barang) yang diadakan sekali tiap 5 tahun belum pernah dilaksanakan dalam 5 tahun terakhir. Untuk Opaname Fisik aset yang tidak bergerak hanya dicatat jenis dan jumlahnya, setelah itu disimpan dalam gudang aset milik dinas. Untuk aset yang bergerak berupa kendaraan dinas langsung diberikan kepada PNS yang belum memiliki kendaraan disertai Berita Acara Serah Terima Barang. Dari hasil wawancara, ternyata banyak aset berupa tanah dan kendaraan dinas yang tidak memiliki surat-surat kepemilikan oleh pemda Yahukimo, sehingga mulai tahun 2015 telah dilakukan pendataan kembali aset-aset Pemda Yahukimo yang berada di luar wilayah Yahukimo. Luas tanah pemda Yahukimo 5.600 ha, pemerintah sudah beberapa kali membayar tanah tersebut ke pemilik hak ulayat namun sampai saat ini belum ada bukti kepemilikan (sertipikat tanah) yang dimiliki oleh pemerintah Kabupaten Yahukimo. Jika dihitung-hitung luas tanah tersebut bernilai sangat besar, sehingga pemda Yahukimo harus cepat menyelesaikan dokumen-dokumen yang berkaitan dengan jual beli tanah pemda tersebut. Dengan gambaran tersebut di atas, pemerintah daerah harus segera menginventarisasi tanah-tanah tersebut untuk kemudian dilakukan sertifikasi aset tanah yang belum jelas status dan kedudukannya.

\section{Pelaporan}

Dari hasil wawancara dengan BPKAD, diperoleh informasi bahwa pelaporan aset secara umum oleh 5 (lima) SKPD sudah berjalan baik namun waktu penyampaian laporan yang belum tepat waktu. 
Penyampaian laporan pengelolaan barang SKPD ke BPKAD dilakukan di akhir tahun anggaran, yang seharusnya disampaikan per semester. Ini diakibatkan karena penyelesaian pekerjaan kontrak selesai di akhir tahun. Dari sekian SKPD di Kabupaten Yahukimo, baru 7 (tujuh) SKPD yang taat dalam penyampaian laporan pengelolaan BMD ke Badan Pengelolaan Keuangan dan Aset Daerah Kabupaten Yahukimo. Disini terlihat jelas bahwa pelaporan barang milik daerah bukan kewajiban karena tidak adanya sanksi yang diberikan kepada SKPD terkait tertib administrasi pelaporan, hal ini didukung oleh pernyataan Kasie. Inventarisasi dan Mutasi Aset BPKAD Kab. Yahukimo :

"banyak SKPD tidak menyampaikan laporan aset karena tidak adanya sanksi tegas dari pemda, (Robert Rantung, S.E. Kasie. Inventarisasi dan Mutasi Aset BPKAD Kab. Yahukimo)"

Pelaporan barang milik daerah yang telah dibuat baru sebatas penyampaian dokumen laporan penerimaan/perolehan, sedangkan SKPD lainnya belum dapat menyampaikan laporan pengelolaan BMD sesuai ketentuan yang berlaku. Hal ini dikuatkan dengan pernyataan Kasie. Inventarisasi dan Mutasi Aset Bidang Aset BPKAD Kab. Yahukimo:

"ada 7 (tujuh) SKPD yang sudah tertib memasukkan laporan pengelolaan aset SKPD pada akhir tahun, sementara laporan per semester belum ada yang membuat, (Robert Rantung, S.E. Kasie. Inventarisasi dan Mutasi Aset BPKAD Kab. Yahukimo)"

Pada tahun 2016, direncanakan pelaporan aset dilakukan secara online dengan cara bendahara barang tiap SKPD membuat laporan secara manual ke BPKAD dan BPKAD yang akan menginput laporan SKPD ke Server yang berada di Yogyakarta. Dengan demikian, semua aset BMD Kabupaten Yahukimo dapat diakses oleh semua orang secara online. Hal ini diungkapkan oleh Kasie. Inventarisasi dan Mutasi Aset Bidang Aset BPKAD Kab. Yahukimo :

"pertengahan tahun 2015 mulai dicoba aplikasi komputerisasi pengelolaan aset sehingga pelaporan aset SKPD tahun 2016 dilakukan secara online, (Robert Rantung, S.E. Kasie. Inventarisasi dan Mutasi Aset BPKAD Kab. Yahukimo)"

Ada beberapa aset Kabupaten Yahukimo yang masih dikuasai oleh masyarakat berupa tanah. Hal ini dikarenakan tidak adanya sertipikat tanah sebagai bukti kepemilikan daerah. Dalam penelitian $\mathrm{Na}$ (2009) yang 
melakukan penelitian mengenai analisis manajemen aset tetap tanah dan bangunan milik pemerintah daerah (studi di Kabupaten Aceh Barat), menyimpulkan bahwa variabel yang memiliki tingkat kepentingan yang tertinggi adalah variabel pendaftaran (sertifikasi) terhadap aset tanah. Sementara variabel yang memiliki tingkat kinerja (performance) yang rendah adalah profesionalisme sumber daya manusia dalam mengelola dan memanfaatkan aset tanah. Ada juga asset kendaraan yang sudah rusak tetapi tidak dilaporkan oleh pemegang kendaraan sehingga sulit untuk dilakukan penghapusan dan sampai saat ini masih tercatat dalam KIB B (Peralatan dan Mesin). Penjelasan diatas berdasarkan petikan wawancara penulis dengan Kasie. Inventarisasi dan Mutasi Aset BPKAD Ka. Yahukimo :

"sering bendahara barang SKPD tidak melaporkan aset yang rusak dan tidak berfungsi seperti peralatan computer dan kendaraan dinas sehingga membebani pembukuan aset daerah, (Robert R., S.E. Kasie. Inventarisasi dan Mutasi Aset BPKAD Kab. Yahukimo)"

Pelaksanaan pengelolan BMD yang dilaksanakan pada beberapa SKPD terkendala dalam proses penatusahaanya yaitu belum adanya tanggungjawab dari masing-masing staf atau pejabat dalam pengelolaan barang milik daerah dimana didapat ada beberapa SKPD yang sering telat dalam penyampaian laporan padahal sudah sering diingatkan kembali sehingga bagi Badan Pengelolaan Keuangan dan Aset Daerah Kabupaten Yahukimo akan berdampak pada penyajian laporan barang milik daerah yang tidak akurat selain itu dalam pelaksanaan penatusahaan yang menjadi penghambat dalam pengelolaannya adalah selain sumber daya manusia dari segi jumlah dan kualitas. Badan Pengelolaan Keuangan dan Aset Daerah Kabupaten Yahukimo belum mempunyai dana yang memadai untuk melaksanakan kegiatan demi menunjang pelaksanaan penatausahaan yang baik. Kenyataan ini tentunya harus diperhatikan dan diperlukan solusi yang tepat supaya proses pengelolaan barang milik daerah dalam tahap penatausahaan barang milik daerah berjalan dengan baik sehingga tercipta adanya aparatur yang profesional dalam menangani masalah pengelolaan barang milik daerah. Boimau (2012) melakukan penelitian tentang pengelolaan aset tetap (tanah dan bangunan) di Pemerintah Kabupaten Timor Tengah Selatan. Hasil penelitian menunjukkan bahwa paling berpengaruh dalam optimalisasi aset 
Pemerintah Kabupaten Timor Tengah Selatan secara berturut-turut adalah kriteria penatausahaan, pemanfaatan aset dan penilaian aset. Ini terlihat bahwa penatausahaan BMD merupakan hal penting dalam pengelolaan BMD.

Manfaat dari penatausahaan asset pada Dinas Kehutanan Kabupaten Yahukimo adalah:

a. Meningkatkan akuntabilitas

b. Meningkatkan manajemen pelayanan

c. Meningkatkan efisiensi keuangan karena tidak setiap tahun melakukan pengadaan barang dan jasa pemerintah.

\section{KESIMPULAN}

Kesimpulan yang dapat diambil dari hasil penelitian yang dilakukan penulis sebagai berikut :

1. Kegiatan pembukuan dalam penatausahaan BMD dipengaruhi oleh faktorfaktor sebagai berikut :

a) Kurangnya jumlah tenaga bendahara barang di setiap SKPD, karena setiap SKPD tidak memiliki pembantu bendahara barang;

b) Kurangnya kualitas SDM pengelola barang karena minimnya mengikuti bimbingan teknis pengelolaan BMD;

c) Kurangnya dana pengelolaan BMD;

d) Kurangnya adanya koordinasi bendahara barang dengan Bidang Aset di BPKAD;

2. Kegiatan Inventarisasi dalam penatausahaan BMD dipengaruhi oleh faktorfaktor sebagai berikut:

a) Keterbatasan tenaga inventarisasi,

b) Belum tersedianya biaya untuk sensus barang/inventarisasi

c) Kualitas SDM yang ada belum mampu untuk melakukan inventarisasi sehingga Sensus Barang SKPD belum dilakukan inventarisasi dan pemberian label sesuai ketentuan yang berlaku.

3. Kegiatan Pelaporan dalam penatausahaan BMD dipengaruhi oleh faktorfaktor sebagai berikut :

a) Belum adanya sanksi tegas bagi yang lambat dan/atau tidak membuat Laporan BMD dan penghargaan bagi yang sudah tertib menyampaikan laporan pengelolaan BMD di SKPD; 
b) Aset yang rusak tidak dilaporkan sehingga masih terhitung sebagai aset walaupun sudah tidak berfungsi;

c) Kurangnya kualitas SDM bendahara barang di SKPD;

d) Komitmen pimpinan yang kurang memberikan pembinaan terhadap profesionalitas PNS;

\section{SARAN}

Dari kesimpulan di atas, ada beberapa saran yang dapat penulis sampaikan sebagai berikut :

a. Harus ada sanksi bagi SKPD yang terlambat atau tidak melaporkan pengelolaan BMD dan penghargaan bagi SKPD yang tertib dalam penatausahaan BMD.

b. Sebaiknya dalam pengelolaan barang milik daerah agar lebih baik dan tertib, sumber daya aparatur pengelola barang milik daerah harus sering diikutkan dalam diklat dan bimtek pengelolaan BMD agar lebih terampil dan berkualitas serta menerapkan suatu sanksi agar terciptanya ketaatan ataupun kepatuhan sehingga penyimpangan maupun kelalaian dalam penerapan pengelolaan barang dapat terhindari.

c. Perlunya komitmen pimpinan dalam hal peningkatan karier bendahara barang di setiap SKPD, sehingga profesionalisme dapat terus ditingkatkan.

d. Pengelolaan barang milik daerah pada BPKAD Kabupaten Yahukimo yang relatif besar dan banyak jenis barangnya, memerlukan adanya integrasi dalam aplikasi SIMBADA serta SIKD sehingga akan mempermudah dalam penyajian laporan.

e. Diharapkan kepada Pemerintah Kabupaten Yahukimo untuk dapat mengalokasikan dana yang lebih besar dalam penataan aset/BMD di Kabupaten Yahukimo.

f. Untuk dapat menginventarisir aset tanah ke dalam SIMBADA secara akurat, sebaiknya Pemda lebih meningkatkan lagi koordinasi dan konsolidasi penginventarisasian aset tanah milik Pemda Yahukimo kepada seluruh SKPD selaku pengguna.

g. Pemda juga sebaiknya mengusulkan adanya tambahan pegawai di bidang Pengamanan agar dapat meningkatkan efektivitas pengamanan aset secara fisik dan juga agar dapat melakukan pengawasan dan pengendalian terhadap aset tanah milik Pemda yang rawan dikuasai 
maupun diklaim oleh pihak ketiga tanpa adanya hubungan hukum yang jelas yang bisa merugikan Pemda.

h. Untuk mengatasi adanya gugatan perkara sengketa yang dilayangkan pada Pemda, sebaiknya Pemda segera melakukan sertifikasi aset tanahnya yang belum jelas status dan kedudukannya.

\section{DAFTAR PUSTAKA}

BPK RI Perwakilan Papua. 2012. Laporan Hasil Pemeriksaan BPK RI Atas Laporan Keuangan Pemerintah Daerah Kabupaten Yahukimo Tahun 2012.

Buletin Teknis Standar Akuntansi Pemerintah Nomor 09 tentang Akuntansi Aset Tetap.

Boimau, Daniel Jorhans Paulus, 2012, "Pengelolaan Aset Tetap (Tanah dan Bangunan) pada Pemerintah Daerah Kabupaten Timor Tengah Selatan",Tesis S-2 Program Pascasarjana UGM,Yogyakarta (tidak dipublikasikan). https://repository.ugm.ac.id/id/eprint/91153

Mardiasmo, 2002. Otonomi dan Manajemen Keuangan Daerah, ANDI, Yogyakarta.

Siregar, Doli, D., 2002, Optimalisasi Pemberdayaan Harta Kekayaan Negara: Peran Konsultan Penilai Dalam Pemulihan Ekonomi Nasional, PT Gramedia Pustaka Utama, Jakarta.

Siregar, Doli, D., 2004. Manajemen Aset. PT Gramedia Pustaka Utama, Jakarta.

Sugiyono.2008. Metode Penelitian Pendidikan. Penerbit Alfabeta Bandung..

Sumini dan Pangaribuan, Oktavia Ester. 2010. Modul Penggunaan, Penggamanan dan Pemeliharaan BMD, Kementerian Keuangan Republik Indonesia, Badan Pendidikan dan Pelatihan Keuangan, Pusdiklat Kekayaan Negara dan Perimbangan Keuangan. 